\title{
Application Research on Toughness Index CTOD in Design of Railway Steel Bridge
}

\author{
Yuling Zhang ${ }^{1,2}$, Jiyan $\operatorname{Pan}^{2}$ and Jiluan $\operatorname{Pan}^{3}$ \\ 1. School of Civil Engineering, Zhejiang Shuren University, Hangzhou 310015, China \\ 2. Railway Engineering Research Institute, China Academy of Railway Sciences, Beijing 100081, China \\ 3. Department of Mechanical Engineering, Tsinghua University, Beijing 100084, China
}

\begin{abstract}
Railway steel bridge belongs to large-scale weld structures suffered with cyclic dynamic stress generated by the train. In recent years, the section of bridge member becomes bigger, plate becomes thicker, connection form becomes more complicated and steel bridge is applied to wider districts even in the lower temperature environment. Thus, fatigue and fracture problems become more serious. On the basis of CTOD (crack tip open displacement) test data of 372 specimens tested in different temperatures, this paper discusses research work about fracture proof design that involves how to determine the criterion of CVN (Charpy V-notch) impact toughness by establishing the relationship between CTOD and CVN, how to prevent from brittle fracture by stress control in railway steel bridge design based on COD (crack open displacement) design curve through the test data and how to do the fatigue design for railway steel bridge at $-50{ }^{\circ} \mathrm{C}$ of design temperature in an easy way. The method of fatigue design at $-50{ }^{\circ} \mathrm{C}$ environment has been used for railway steel bridge structure of Qinghai-Tibet Railway in China.
\end{abstract}

Key words: Fracture proof design, fatigue at low temperature, CTOD test, toughness criterion.

\section{Introduction}

Fatigue fracture is one of the most important contents in design of railway steel bridge that belongs to large-scale weld structure suffered with heavy cyclic dynamic stress generated by the train. In recent years, the section of bridge member becomes bigger, plate becomes thicker, connection form becomes more complicated and steel bridge is applied to wider districts even in lower temperature environment so as to meet the needs of construction development in China. Fatigue and fracture problems are becoming more serious. Traditional design concept and method are just focused on building steel bridge in the south part of China with warm weather, lacking enough experience for using steel bridge in cold weather, so it is necessary to supplement special regulation or renew the research method. It was given by the engineering

Corresponding author: Yuling Zhang, Ph.D., research fellow, research fields: steel bridge, fatigue and fracture, steel material used in bridge and railway train loading standard. E-mail: zyl@rails.cn. test research [1] that fatigue strength is higher when specimen is at lower temperature than it is at room temperature, which is about $20^{\circ} \mathrm{C}$, in comparison tests. The conclusions were doubtable and not reasonable either [2]. With the cognition developed, the idea that elastic-plastic fracture toughness has to be applied to fracture proof design in railway steel bridge formed and expected to obtain reasonable interpretation and solve the fatigue problems as well when the steel bridge serving in lower temperature. A series of CTOD (crack tip open displacement) tests followed by standard [3] were carried out in different temperatures to the common bridge steel, Grades Q370qE and Q345qD, with the thickness of 12, 16, 24, 32, 44 and $50 \mathrm{~mm}$ both for base metal and butt weld seam. The total numbers of specimen were 372 and the effective test data were 364. CTOD test was done by straight three-point bending specimen. The regression data point for weld seam and the relationship between CTOD and temperature after regression [4] are shown in Fig. 1. 


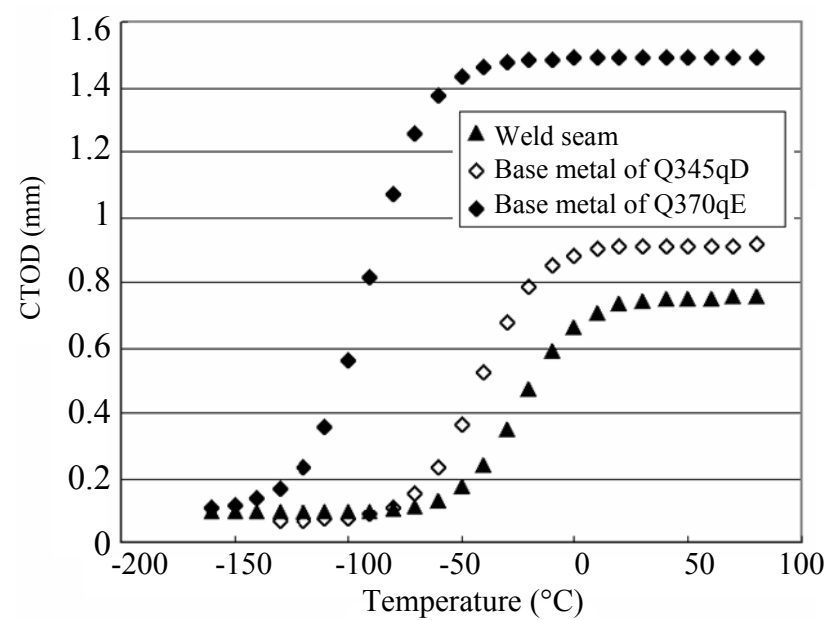

Fig. 1 CTOD versus temperature of base metal and weld seam.

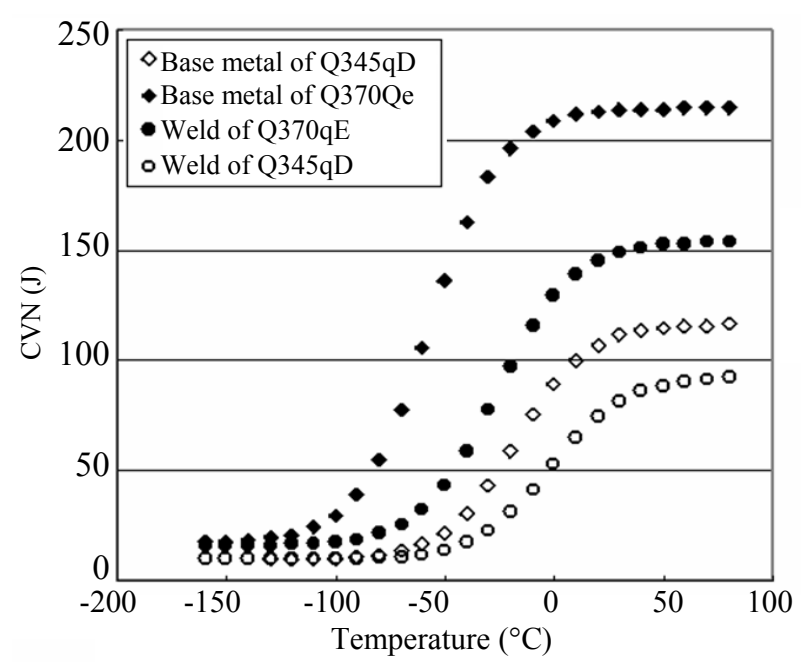

Fig. 2 CVN versus temperature of base metal and weld.

CVN (Charpy V-notch) impact toughness is an important index proving toughness quality of steel material and weld joint. It is applied to engineering widely because of its simple and inexpensive test procedure compared with CTOD. In order to get the relationship between the two toughness indexes, 702 specimens of CVN impact test were carried out in different temperatures accordingly $[5,6]$. The regressed curve is shown in Fig. 2.

Three aspects of research are carried out around fatigue, fracture problem based on the test data of CTOD and CVN:

(1) to create the relationship between CTOD and CVN by absorption energy at the moment of specimen damaged in test, to find the basic CVN impact toughness of weld joint proof brittle fracture and then to determine the toughness criterion that should be easy and practical;

(2) to find special stress calculation formula for railway steel bridge to check and control maximum stress level preventing from brittle fracture when the material and section of bridge member have been the fact;

(3) to determine the complementary requirement and provide method for fatigue design temperature at the temperature of $-50{ }^{\circ} \mathrm{C}$ to apply to Tsinghai-Tibet Railway line. The research result will be the reference of revising the code later.

\section{Weld Toughness Criterion}

So far, the major way to control toughness of steel material in engineering is to check the impact energy by CVN impact test. In bridge design, the first thing is to choose material and confirm the toughness criterion. Usually, the lowest impact toughness criterion is determined by comparing with the similar bridge and accumulated experience, which causes a lot of discussion and dispute. The better way to make sure the criterion is by means of CTOD test data, since it can be leant clearly that which situation would generate brittle fracture and ductility damage. In this way, it can help to determine the toughness criterion. However, CTOD test is complicated comparatively and is unapt to inspect as a normal way in engineering. Therefore, the absorption energy is taken as the instrumentality to establish the relationship between CTOD and CVN. The test record of vertical replacement at load point and loading value are utilized to get the basic absorption energy in CTOD test, and then, it can be used as a guide to work out the basic CVN impact toughness criterion. The idea comes from the CTOD test data within temperature from $20{ }^{\circ} \mathrm{C}$ to $-70{ }^{\circ} \mathrm{C}$. It shows that the basic absorption energy provided by specimen is independent of test temperature when it gets to certain 
CTOD value. On one side, it can also lead to the impact toughness for real bridge under the temperature from room temperature to $-70{ }^{\circ} \mathrm{C}$ which should satisfy with basic absorption energy obtained from certain critical state in CTOD test. On the other side, the relationship should also be analyzed between loading rate of velocity and character temperature for CTOD test, CVN impact test and service train passing bridge, by which the test temperature is confirmed for doing impact test. Consequently, the reasonable impact toughness criterion with large amount of test basis can be prescribed.

The following regulations should be complied in analysis:

(1) It is required for material to have the absorption energy ability that can suffer the destroy state with transition ability from brittleness to ductility. In other words, when the structure gets to fracture, the maximum stress in member section would exceed yield strength and the structure should have a certain deformation;

(2) Two times the variance are added to the average value of the CTOD test data in statistics of the relationship between CTOD and CVN to make conservative.

\subsection{Method to Confirm Basic Toughness Index}

The steps to determine the toughness criterion are followed by the following items:

(1) Calculate integral to obtain the absorption energy by the test record of vertical replacement at load point and loading value;

(2) Get the transition coefficient between CVN and CTOD test. Analysing the differences between CTOD test and CVN impact test, they are the content of the absorption energy, the size of the sample and loading rate of velocity. It can be resolved into elastic energy, crack produced energy and crack extended energy for the absorption energy in CVN impact test, but no crack produced energy is included in the absorption energy in CTOD test. This difference shows that
CTOD test is more acute. The size of sample for CVN impact test is $10 \times 10 \times 55 \mathrm{~mm}$ with $10 \times 8 \mathrm{~mm}$ of loading net area ( $2 \mathrm{~mm}$ of notch is taken out) and 40 $\mathrm{mm}$ of loading span. For CTOD test, the size of sample is $B \times 2 B \times 10 B \mathrm{~mm}$ with $B \times B \mathrm{~mm}$ of loading net area ( $B \mathrm{~mm}$ of prefabricated fatigue crack are taken out) and $8 B$ of loading span, where $B$ is the thickness of steel plate. The equivalent size of sample from CTOD to CVN is deduced according to the energy during loading in both tests in Eq. (1):

$$
P_{f}=P \cdot \frac{P l^{3}}{48 E I}=P \cdot \sigma \cdot \frac{l^{2}}{6 E y}
$$

where, $P=$ test load; $\sigma=$ the maximum stress in net area; $l=$ loading span of test sample; $E=$ elasticity modulus; $y=$ anti-bending height of rectangle cross section. Put the size of CVN and CTOD samples into Eq. (1), respectively, and suppose that the transition coefficient between CVN and CTOD test is shown as: $C_{e}=\frac{A_{C T O D}}{A_{C V N}}$, then $C_{e}=0.32 B$, where, $A_{\text {СТОD }}$ and $A_{C V N}=$ absorption energy in CTOD test and in CVN impact test (J); $C_{e}=$ transition coefficient; $B=$ thickness of CTOD specimen. The difference of loading rate of velocity will be discussed in Step (4);

(3) Sort the test data from CTOD test that were damaged at the transition situation from brittle to ductility, pick up their absorption energy in list, and calculate the basic energy value that is corresponding to the specimen condition that is impossible to generate brittle fracture;

(4) Determine test temperature. It is shown from the CTOD test that the basic absorption energy provided with a specimen, when the crack tip inside of the specimen opens a certain displacement, is independent of temperature when the thickness of the specimen is the same. Meanwhile, in practical bridge, the narrowest open displacement should be controlled mainly. Therefore, there is no need to consider under what temperature the CTOD test is done corresponding to absorption energy in Step (3) above, just consider the difference of the loading rate of 
velocity in CTOD test and CVN impact test. It mainly affects the exact place where the toughness-temperature character curve located on the temperature coordinate.

The analysis about temperature coordinate is shown below:

(1) As per the relation of character temperature point between fracture toughness stress intention factor $K_{I C}$ that is tested by static or equivalently static loading and the loading rate of velocity caused by service train, the character temperature of service train is equivalent to increase $\Delta T_{1}\left({ }^{\circ} \mathrm{C}\right)$ by static $K_{I C}$ test [7]. It can be shown in Eq. (2):

$$
\Delta T_{1}=\left(83-0.08 \sigma_{s}\right) \varepsilon^{0.17}
$$

where, $\varepsilon=$ loading rate of strain velocity $\left(\mathrm{s}^{-1}\right)$;

(2) As per the relation of character temperature point between the loading velocity caused by service train and impact toughness test, the character temperature of service train is equivalent to decrease $\Delta T_{2}\left({ }^{\circ} \mathrm{C}\right)$ from impact toughness test [8]. It can be shown by Eq. (3):

$$
\Delta T_{2}=70{ }^{\circ} \mathrm{F}=39{ }^{\circ} \mathrm{C}
$$

(3) The test character temperature replacement in impact test between loading slowly and normal loading speed in engineering can be represented by $\Delta T_{3}[9]$ :

$$
\Delta T_{3}=120-0.121 \sigma_{s}\left({ }^{\circ} \mathrm{C}\right)
$$

(4) As per the relation of character temperature point between fracture toughness CTOD that is tested by static or equivalently static loading and CVN impact toughness test, the character temperature of CTOD test is equivalent to decrease $\Delta T_{4}\left({ }^{\circ} \mathrm{C}\right)$ from impact toughness test according to the test in comparison above:

$$
\Delta T_{4}=[15,35]\left({ }^{\circ} \mathrm{C}\right)
$$

Taking bridge steel Q370qE as an example, the relationship of character temperature coordinate above is summed up and drawn in Fig. 3.

Compared with the five situations in Fig. 3, the character temperature of CTOD test is higher than that under loading rate of velocity caused by service train, even though it is static loading. It is understood that the loading way in CTOD test is three points bending, and the notch is sharp fatigue crack, which is very severe situation. As a result, the character temperature of service train is replaced by CTOD test temperature on the safe side, including the effect of temperature at the bridge location and loading rate of velocity. And then, the temperature replacement value from bridge site temperature to impact test is confirmed based on the character temperature relationship between CTOD and CVN test.

\subsection{Analysis Result and Application}

Followed by the steps above, the basic indexes of impact toughness proof brittle fracture are obtained in Table 1.

The stipulation of steel material about the lowest impact toughness in national standard is classified by test temperature into $0,-20$ and $-40{ }^{\circ} \mathrm{C}$. The steel material used in railway steel bridge is the steel with $-20{ }^{\circ} \mathrm{C}$ and $-40{ }^{\circ} \mathrm{C}$ of requirement. Utilizing the curve equation of railway bridge steel regressed by $\mathrm{CVN}$ test (Fig. 3), the equivalent indexes of the basic impact toughness in Table 1 are compared with the stipulation in national standard, and the commended toughness criterions for railway steel bridge are shown in Tables 2 and 3.

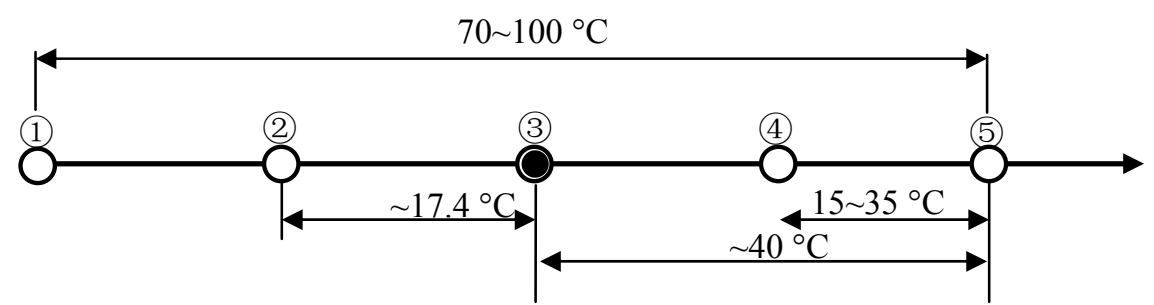

Fig. 3 Comparative character temperature relation (1): Loading slowly in impact test; (2): loading slowly in $K_{I C}$ test; (3): loading velocity caused by service train; (4): loading slowly in CTOD test; (5): loading velocity in CVN impact test). 
Table 1 Basic indexes of CVN impact toughness.

\begin{tabular}{|c|c|c|c|c|c|c|c|c|c|c|}
\hline \multirow[b]{3}{*}{ Material } & & \multirow{3}{*}{$\begin{array}{l}\text { Thickness } \\
(\mathrm{mm})\end{array}$} & \multicolumn{8}{|c|}{ Environment temperature at bridge location } \\
\hline & & & \multicolumn{2}{|c|}{$-50^{\circ} \mathrm{C}$} & \multicolumn{2}{|c|}{$-40^{\circ} \mathrm{C}$} & \multicolumn{2}{|c|}{$-30^{\circ} \mathrm{C}$} & \multicolumn{2}{|r|}{$-20^{\circ} \mathrm{C}$} \\
\hline & & & Energy $(\mathrm{J})$ & $\begin{array}{l}\text { Test } \\
\text { temperature } \\
\left({ }^{\circ} \mathrm{C}\right)\end{array}$ & $\begin{array}{l}\text { Energy } \\
\text { (J) }\end{array}$ & $\begin{array}{l}\text { Test } \\
\text { temperature } \\
\left({ }^{\circ} \mathrm{C}\right) \\
\end{array}$ & $\begin{array}{l}\text { Energy } \\
(\mathrm{J})\end{array}$ & $\begin{array}{l}\text { Test } \\
\text { temperature } \\
\left({ }^{\circ} \mathrm{C}\right) \\
\end{array}$ & $\begin{array}{l}\text { Energy } \\
\text { (J) }\end{array}$ & $\begin{array}{l}\text { Test } \\
\text { temperature } \\
\left({ }^{\circ} \mathrm{C}\right) \\
\end{array}$ \\
\hline \multirow{3}{*}{ Q370qE } & Base & $\leq 30$ & 45 & -30 & 45 & -20 & 45 & -10 & 45 & 0 \\
\hline & metal & $30-50$ & 70 & -30 & 70 & -20 & 70 & -10 & 70 & 0 \\
\hline & Weld & - & 46 & -35 & 46 & -25 & 46 & -15 & 46 & -5 \\
\hline \multirow{2}{*}{ Q345qD } & $\begin{array}{l}\text { Base } \\
\text { metal }\end{array}$ & $\leq 32$ & 43 & -30 & 43 & -20 & 43 & -10 & 43 & 0 \\
\hline & Weld & & 34 & -35 & 34 & -25 & 34 & -15 & 34 & -5 \\
\hline
\end{tabular}

Table 2 Commended lowest CVN impact toughness criterion.

\begin{tabular}{|c|c|c|c|c|c|c|}
\hline \multirow{3}{*}{ Material } & & \multirow{3}{*}{ Thickness (mm) } & \multicolumn{4}{|c|}{ Environment region and temperature at bridge location } \\
\hline & & & \multicolumn{2}{|c|}{ Region E* } & \multicolumn{2}{|c|}{ Region $\mathrm{D}^{*}$} \\
\hline & & & Energy (J) & $\begin{array}{l}\text { Test } \\
\text { temperature }\left({ }^{\circ} \mathrm{C}\right)\end{array}$ & Energy $(\mathrm{J})$ & $\begin{array}{l}\text { Test } \\
\text { temperature }\left({ }^{\circ} \mathrm{C}\right)\end{array}$ \\
\hline \multirow{3}{*}{ Q370qE } & \multirow{2}{*}{ Base metal } & $\leq 30$ & 41 & -40 & 41 & -20 \\
\hline & & $30-50$ & 70 & -40 & 70 & -20 \\
\hline & Weld & - & 41 & -40 & 41 & -20 \\
\hline \multirow{2}{*}{ Q345qD } & Base metal & $\leq 32$ & 34 & -20 & 34 & -20 \\
\hline & Weld & - & 30 & -20 & 30 & -20 \\
\hline
\end{tabular}

* See Table 3 .

Table 3 Region distribution for constructing bridge in China.

\begin{tabular}{lll}
\hline Region mark & Name of territory & Extreme temperature in history $\left({ }^{\circ} \mathrm{C}\right)$ \\
\hline \multirow{2}{*}{ E } & Heilongjiang, Sinkiang, Inner Mongolia, Tibet, Jilin, Shanxi, Tsinghai & -40 below \\
& Liaoning, Gansu, Szechwan, Hebei, Shannxi, Ningxia & -30 to -40 \\
\hline \multirow{2}{*}{$\mathrm{D}$} & Beijing, Tientsin, Shandong, Henan & -20 to -30 \\
& Other & -20 above \\
\hline
\end{tabular}

\section{Control Stress against Brittle Fracture}

It is found that, by observing CTOD test process, controlling action force on structure less than the force that would arouse brittle fracture can also prevent structure from brittle fracture. The purpose of this research is for the existing bridges since their toughness situation had already been the fact. The controlling stress equation for railway steel bridge to prevent from brittle fracture can be deduced by means of the brittle fracture data in CTOD tests [4]. Eqs. (6) and (7) are for base metal and weld seam, respectively:

$$
\frac{\sigma}{\sigma_{s}} \leq \frac{1}{1.12} \sqrt{\frac{E \delta}{2 \pi a \sigma_{s}}}-0.6
$$

$$
\frac{\sigma}{\sigma_{s}} \leq \frac{1}{1.12} \sqrt{\frac{E \delta}{2 \pi a \sigma_{s}}}-0.3
$$

where, $\sigma=$ working stress; $\sigma_{s}=$ yield strength; $E=$ elasticity modulus; $\delta=$ CTOD value from test; $a=$ crack length.

\subsection{Analysis Result}

To base metal of Q370qE, $E=2.1 \times 10^{5} \mathrm{MPa}$, average yield strength $\bar{\sigma}_{s}=385 \mathrm{MPa}$, CTOD value from tests is shown in Eq. (8):

$$
\delta=\frac{a}{B}\left[0.1059+\frac{1.383}{1+e^{-0.0778(T+90.666)}}\right]
$$

substitute them into Eq. (6), then: 
$\sigma \leq 3,202.82 \sqrt{\frac{1}{B}\left[0.1059+\frac{1.383}{1+e^{-0.0778(T+90.666)}}\right]}$

$-269.25$

To weld joint accordingly, $E=2.1 \times 10^{5} \mathrm{MPa}$, $\bar{\sigma}_{s}=385 \mathrm{MPa}$, (taking average yield strength of base metal for Q345qD and Q370qE that are on safe side), CTOD value from test is shown as Eq. (10):

$$
\delta=\frac{a}{B}\left[0.0918+\frac{0.6615}{1+e^{-0.0767(T+24.1927)}}\right]
$$

substitute them into Eq. (7), then:

$\sigma \leq 3,169.37 \sqrt{\frac{1}{B}\left[0.0918+\frac{0.6615}{1+e^{-0.0767(T+24.1927)}}\right]}-101$

where, $B=$ thickness of steel plate; $T=$ working temperature on site.

Calculating by Eqs. (10) and (11), the available maximum working stress $\sigma$ without occurring brittle fracture to different thickness of bridge member can be obtained.

\subsection{Application}

Supposing that $\alpha$ is available stress coefficient, and $\alpha=\frac{\sigma}{\sigma_{s}}$, the calculation results to bridge steel Q370qE, Q345qD and weld are shown in Table 4.

Usually, the ratio of design stress to yield strength is 0.58 . Compared with the values in Table 4 , it can be concluded that when the weld is used at the temperature of $-40{ }^{\circ} \mathrm{C}$ to $-50{ }^{\circ} \mathrm{C}$, some available stress is less than its design stress. It means that even though those members with the weld suffered the action stress that is below the allowable value in design code, brittle fracture may happen at some moment. In this way, reducing working stress calculated by the method above can stop some brittle fracture.

\section{Fatigue Design Method of Steel Bridge at Low Temperature}

Tsinghai-Tibet railway line is located at high altitude and cold region in China, where the extreme lowest temperature is $-45^{\circ} \mathrm{C}$, with undeveloped traffic and atrocious environment. The length of bridge within iced soil region exceeds $70 \mathrm{~km}$. In order to solve the problem of long construction period for concrete bridge, the steel-concrete composite bridges were used and the test investigation was carried out since the environment temperature is out of the range of design code, and the brittle fracture may happen at some moment. In this way, reducing working stress calculated by the method above can stop some brittle fracture. A series of research projects for bridges in Tsinghai-Tibet railway line were carried out. As per steel girder of composite bridge, the major effect under those bad conditions caused by the peculiar geography environment is the perennial cold weather. Low temperature would reduce toughness of steel and weld joint, make material brittle, bring structure to a lower fatigue performance and therefore reduce safety

Table 4 Maximum available stress coefficient $\alpha$.

\begin{tabular}{lllllllllllll}
\hline \multirow{2}{*}{ Material } & \multicolumn{1}{l}{ Temperature } & \multicolumn{10}{c}{ Thickness of steel plate $(\mathrm{mm})$} \\
\cline { 2 - 13 } & $\left({ }^{\circ} \mathrm{C}\right)$ & 12 & 16 & 20 & 24 & 30 & 32 & 38 & 40 & 44 & 50 \\
\hline \multirow{2}{*}{ Base metal of Q370qE } & -50 & 1 & 1 & 1 & 1 & 1 & 1 & 1 & 1 & 1 & 1 \\
& -40 to 0 & 1 & 1 & 1 & 1 & 1 & 1 & 1 & 1 & 1 & 1 \\
\hline \multirow{2}{*}{ Base metal of Q345qD } & -50 & 1 & 1 & 1 & 0.95 & 0.79 & 0.75 & - & - & - & - \\
& -40 to 0 & 1 & 1 & 1 & 1 & 1 & 1 & - & - & - & - \\
\hline \multirow{3}{*}{ Weld } & -50 & 1 & 0.97 & 0.83 & 0.74 & 0.63 & 0.60 & 0.53 & 0.51 & 0.48 & 0.43 \\
& -40 & 1 & 1 & 1 & 0.93 & 0.80 & 0.77 & 0.68 & 0.66 & 0.62 & 0.56 \\
& -30 & 1 & 1 & 1 & 1 & 1 & 0.98 & 0.87 & 0.84 & 0.79 & 0.73 \\
& -20 & 1 & 1 & 1 & 1 & 1 & 1 & 1 & 1 & 0.97 & 0.89 \\
& -10 & 1 & 1 & 1 & 1 & 1 & 1 & 1 & 1 & 1 & 1 \\
\hline
\end{tabular}


level of railway steel bridge suffered with very heavy live load. The current fatigue design parameter that is made and used in the structure at common temperature cannot meet the needs of Tsinghai-Tibet railway line.

\subsection{Research Method}

The test of fatigue crack propagation rate was carried out to $24 \mathrm{~mm}$ thickness of Q370qD base steel and weld at $-50{ }^{\circ} \mathrm{C}$. It indicated that, under $-50{ }^{\circ} \mathrm{C}$ temperature, the material coefficients of Paris equation, in the middle part of speed propagation region, $\frac{d a}{d N}=\mathrm{C}(\Delta K)^{\mathrm{m}}$, have smaller " $\mathrm{C}$ " and larger "m" and have higher fatigue crack threshold $\Delta K_{t h}$, compared with $20 \quad{ }^{\circ} \mathrm{C}$. Furthermore, S-N (stress-recycle number) curve at $-50{ }^{\circ} \mathrm{C}$ is above the curve at $20{ }^{\circ} \mathrm{C}$ and the $\mathrm{S}-\mathrm{N}$ curve at $-50{ }^{\circ} \mathrm{C}$ is flatter than the curve at $20^{\circ} \mathrm{C}$ as well, according to the test results [1]. It leads the wrong direction that using common fatigue design method is good enough at low temperature. However, CTOD tests indicate that low temperature at $-50{ }^{\circ} \mathrm{C}$ would reduce the critical crack open displacement and increase the trend to brittle fracture. The average critical CTOD value at $20^{\circ} \mathrm{C}$ is $0.72 \mathrm{~mm}$, while it is only $0.14 \mathrm{~mm}$ at $-50{ }^{\circ} \mathrm{C}$.

Crack length checking can be expressed by Eq. (12) at $20{ }^{\circ} \mathrm{C}$ and Eq. (13) at $-50{ }^{\circ} \mathrm{C}$ according to CTOD test result:

$$
\begin{aligned}
& a \leq \frac{E \delta}{\pi\left(1.12 \sigma+\sigma_{s}+0.3 \sigma_{s}\right)} \\
& a \leq \frac{E \delta \sigma_{s}}{2 \pi\left(1.12 \sigma+0.3 \sigma_{s}\right)^{2}}
\end{aligned}
$$

where, $a=$ crack length; $E=$ elasticity modulus; $\delta=$ CTOD value from test; $\sigma_{s}=$ yield strength; $\sigma=$ working stress.

Taking $E=2.1 \times 10^{5} \mathrm{MPa}, \delta=0.72 \mathrm{~mm}$ at $20{ }^{\circ} \mathrm{C}$ and $\delta=0.14 \mathrm{~mm}$ at $-50{ }^{\circ} \mathrm{C} ; \sigma_{s}=490 \mathrm{MPa}$ at $20^{\circ} \mathrm{C}$, and $\sigma_{s}=512 \mathrm{MPa}$ at $-50{ }^{\circ} \mathrm{C} ; \sigma=200 \mathrm{MPa}$ from allowable design stress in the code, the critical crack lengths are calculated by Eqs. (12) and (13), that is, $a$
$=56 \mathrm{~mm}$ at $20^{\circ} \mathrm{C}$ and $a=17 \mathrm{~mm}$ at $-50{ }^{\circ} \mathrm{C}$.

Transform Paris equation $\frac{d a}{d N}=\mathrm{C}(\Delta K)^{\mathrm{m}}$ into:

$$
N=\int_{a_{0}}^{a_{c i i}} \frac{d a}{\mathrm{C} \Delta K^{\mathrm{m}}}
$$

where, $N=$ cycle number; $a_{0}, a_{c r i}=$ crack initial length and critical crack length; $\mathrm{C}, \mathrm{m}=$ material constants; $\Delta K=$ stress intensity factor range, $\Delta K=Y \Delta \sigma \sqrt{\pi a}$, $Y=$ crack type coefficient and $\Delta \sigma=$ stress range.

It can be taken as a destiny to bridge structure at both room and low temperatures, then:

$$
N=\frac{1}{\mathrm{C} Y^{\mathrm{m}} \Delta \sigma^{\mathrm{m}} \pi^{\frac{\mathrm{m}}{2}}\left(\frac{\mathrm{m}}{2}-1\right)}\left(\frac{a_{0}}{\sqrt{a_{0}^{\mathrm{m}}}}-\frac{a_{c r i}}{\sqrt{a_{c r i}^{\mathrm{m}}}}\right)
$$

\subsection{Research Result}

In Eq. (15), suppose $a_{0}=0.001 \mathrm{~m}, a_{c r i}=0.056 \mathrm{~m}$ at $20{ }^{\circ} \mathrm{C}$ and $a_{c r i}=0.017 \mathrm{~m}$ at $-50{ }^{\circ} \mathrm{C}$, and $\mathrm{m}$ are taken from the test data regressed with $97.7 \%$ probability, $Y$ is taken for the most unfavourable situation in engineering when $a / W=75 \%$, and the life $N$ is taken as the same cycle numbers at both room and low temperatures. The ratio of fatigue stress range between $-50^{\circ} \mathrm{C}$ and $20^{\circ} \mathrm{C}$ is 0.88 .

This calculation result shows that fatigue at low temperature should not be considered as a common fatigue problem. It is mainly because, at low temperature, the critical fracture crack length shortens sharply. Consequently, the fatigue safety level drops, which can be noticed at the obvious intersection moving ahead between crack stable propagation region and sharp propagation region. The only way to solve the problem is to apply fracture mechanics theory and elastic-plastic CTOD test.

As a result, the allowable fatigue design stress range for steel bridge in Tsinghai-Tibet railway line is prescribed to $80 \%$ of the current fatigue design index. At the same time, the further requirements below should be followed:

(1) During design of bridge for Tsinghai-Tibet 
railway line, thinner steel plate should be preferred, so long as its local stabilization can be content;

(2) All of the steel material is required to fine microstructure by raising temperature during steel making to increase stopping-fracture ability;

(3) It should be taken into consideration to choose other kind of structure or connection style rather than to choose thicker plate when fatigue checking cannot pass the regulation at low temperature.

\section{Conclusions}

Fracture mechanics theory combined with the usual way for fatigue and toughness in railway steel bridge can solve the special problem when the environment is in low temperature. Three aspects of research can be concluded as below:

(1) It is feasible to determine impact toughness criterion according to the basic absorption energy of CTOD test that can intuitively provide anti-brittle fracture ability. The criterion in this method easily gives different impact energy requirement in different climate environment region, which is meaningful to steel bridge construction in China;

(2) Additional method based on CTOD test is suggested to check and control the stress level prevented from brittle fracture. It is only needed to know the grade of steel, the thickness of steel plate and working temperature;

(3) The critical fracture crack length becomes shorter at low temperature. Fatigue at low temperature should be considered as a special problem. The allowable fatigue stress range for steel bridge in Tsinghai-Tibet railway line under $-50{ }^{\circ} \mathrm{C}$ is prescribed to $80 \%$ of the current fatigue design value.

\section{References}

[1] Zhang, Y., Liu, X., Pan, J., Tao, X., and Wang, M. 2005. "Fatigue Test Research at Low Temperature for Steel Beam of Concrete-Steel Combined Railway Bridge in Qinghai-Tibet Railway Line." In Proceeding of Qinghai-Tibet Railway Line Symposia on Service Administration and Related Technology, 77-83.

[2] Shul'ginov, B. S., and Matveyev, V. V. 1997. "Impact Fatigue of Low-Alloy Steels and Their Welded Joints at Low Temperature." International Journal of Fatigue 19 (8-9): 621-7.

[3] The State Administration of Quality Supervision, Inspection and Quarantine of the People's Republic of China. China National Standardization Management Committee. 2007. Metallic Materials-Unified Method of Test for Determination of Quasistatic Fracture Toughness, GB/T 21143-2007. China: China Standard Publishing House.

[4] Zhang, Y., Wang, M., Sun, Z., and Tao, X. 2005. "CTOD Performance of Railway Bridge Base Steel and Weld Seams." Journal of Tsinghua University Science and Technology 45 (5): 585-8.

[5] Zhang, Y., Dai, F., Tao, X., and Wang, M. 2004. "Test Analysis of 14MnNbq and 16Mnq Steel and the Welding CVN Impact Toughness." China Railway Science 26 (3): 80-5.

[6] Zhang, Y., Liu, X., and Pan, J. 2005. "Research on Toughness Criterion for Bridge Steel in Railroad." China Railway Science 26 (3): 16-20.

[7] Qian, W., Liu, J., and Jiang, H. 1999. Report on Safe Fracture Selecting Rules of $14 m n n b q$ for Welded Steel Bridge Components. Research report, Science and Technology Developing and Planning Project of Wuhu Yangtze River Bridge.

[8] AREMA (American Railway Engineering and Maintenance-of-Way Association). 2008. AREMA Manual for Railway Engineering. USA: AREMA.

[9] Fisher, J W. 1984. Fatigue and Fracture in Steel Bridges-Case Studies. USA: A Wiley-Interscience Publication. 